\title{
PUBLIC SECTOR ORGANIZATION: WHERE NEXT?
}

\section{Theodor Friedrich Mars}

This article is about the three major neo-liberal innovations in public sector organization of the 1980s: 'regulatory' agencies to eliminate deviant behaviour generated by market failure; the mechanisms for contracting out or buying in goods and services; and the restructuring of public action into programmes of 'service delivery' to citizens. These have been inserted into public sectors all over the world during the last decade, with effects varying with context and substantive content of public action. The aim here is to discuss the organizational properties of these mechanisms, the range of practical problems they pose for public employees and some ways in which these might now be fruitfully thought about. The stress throughout is not on how things must necessarily work out, but on the dynamics of choice, what choices can and should be made.

\section{PUBLIC SECTOR ORGANIZATION: A GUIDE TO THE RUINS}

New ideas about public sector organization emerged in the later 1970s from the rejection of the established form of diagnosis and prescription: the tradition of 'administrative reform' (Caiden 1969). What had by then come to be referred to pejoratively as 'administrative tinkering' ceased to be accepted by Western governments and international development agencies as an authoritative guide to issues of public sector organization.

The motives behind this rejection are easy enough to understand. The administrative science that developed from the 1930s onwards was very much a part of the post-war political consensus. It claimed to be able to bring effectiveness, efficiency and economy of effort to the pursuit of any purpose to be achieved by collective effort, regardless of the context, whether that of state, market or anything else. The famous Brownlow Committee in the US postulated the existence of 'canons of efficiency' which 'emerged universally wherever men have worked together for some common purpose, whether through the state, the church, the private association, or the commercial enterprise'. (Report 1937:2). Public administration was the mechanism for marrying organizational virtue to political democracy.

With the revival of economic liberalism, this administrative tradition came under fire for claiming something that properly belonged to the market alone. Three classic arguments about structuring in the public sector came to be contended. One was the organizational ('functional') rationale of hierarchical relationships which if properly designed, was said to ensure unity of purpose, proper supervision, unambiguous instruction, long term foresight, personal responsibility and the extraction of appropriate effort (Jaques 1976). A second line of argument sought to show how any organization could benefit from the division of labour, by taking advantage of economies of scale and the complex combination of different forms of expertise.

A third avenue of investigation had developed the notion of the 'rationality' of collective action, by which was meant choosing the one best means of achieving a given end. Methods were developed for progressively breaking down a broad purpose into sub-goals until the level of individual or small group tasks was reached. Each level of sub-goals could then be unambiguously treated purely as a means to the ends specified at each successive level upwards (Simon 1976).

After the Second World War increased attention was devoted to the relation between organizations and what lay outside them. Since their environment was infinite, some selection had to be undertaken. The most common of these was some kind of input-output distinction together with feedback, so that an internal organization is devised to make possible the choice of an appropriate combination of sources of input and destination of outputs.

The ideas about the market popularized in the $1970 \mathrm{~s}$ were in exact parallel to and in rebuttal of these claims. In place of the functional role of hierarchy, the market achieved the 'coordination' of independent agents. Instead of an artificial division of labour, the market was a process of exchange through which everyone spontaneously found their optimal niche. The impossibly difficult process of rationalization is replaced by prices as signals to each individual of the overall situation. The complex and erratic cybernetic steering system which is bound to go wrong is contrasted with the simple and clear 'consumer sovereignty' of the market, with its mechanisms which align production with the demands expressed on the market.

\section{Administrative structure: the end}

The whole way in which the central issues of public sector organization had been traditionally formulated 
was thrown in doubt - the shape of hierarchy, the form of the division of labour, the mechanisms of rationalization and the process of systems maintenance vis-à-vis an environment. How these had been resolved constituted the core features of the 'blueprints' of organization, its organization chart.

An alternative emerged from an analysis of what could go wrong with any structure which worked against rather than with the market. One thing that had happened was what was variously described as rentseeking, monopolies, vested interests, professional power, the tyranny of trades union bosses, artificial job creation, or, to put it bluntly, the concealed theft of what properly belonged to others. The other defect that had vitiated public sector organization was the creation by collectivist politicians of constituencies with a vested interest in their continuation in power. Economic administration had thus come to be about the creation of a vested interest in inflation; industrial administration about feather-bedding manufacturers and guaranteeing jobs; welfare administration about the creation of a sub-class of dependants on state handouts; and health administration about producing a constant supply of sick people for an ever increasing number of doctors to treat at public expense. The two processes mutually stimulated one another. Their prevalence was never demonstrated; all that was necessary was to suggest that these were sentiments about the public sector which were widely shared outside it. Homo sapiens had, it was suggested, been transformed into a creature perpetually in search of a free lunch.

What enabled all this to occur was bureaucracy, the power of officials. This issue certainly brought in to the glare of daylight an aspect of administrative structure which had tended to be glossed over. Organizational structure is a sub-set of relationships whose terms it is a matter of obligation to observe: its breach is deserving of punishment. What administrative doctrines had done was to allocate power to officials. When officials were allocated a 'sphere of responsibility' it was not some onerous imposition: what was actually being done was to create what officials called 'territory' with the right to discourage trespassers. When officials were charged with a 'duty' to do something they were in fact being given the power of compulsion over others which was in their own judgment necessary to carry out their function. Failure was met routinely by the demand for more such powers: this was the real meaning of boundary maintenance. What rationality had come to mean in practice was the parcelling out of decisions to professional groups whose judgment was immune to challenge. It was doctors, teachers and engineers who decided in practice what was to be done. Everyone else was left merely with paying the bills.
If this analy sis seemed at times to have the subtlety of a charging bull in a confined space, it nevertheless found the jugular vein of the old order. Although the issue of the 'structure' of public sector organization had come to be discussed in seemingly technical terms it was in fact a moral economy of public power. This is why such seemingly innocuous questions were always heavily contested. Structure had nothing to do with effectiveness, efficiency and economy of action; and everything to do with who allocated public resources and in whose pockets public resources landed up. Administrative science had taken on, as its commentators had long pointed out (Waldo 1948), the role of an ethical doctrine: a collectivist version of utilitarianism, through which the state assumed the power to assign pleasures and pains according to a social calculus designed for the convenience of politicians and officials.

The structural innovations of the 1980s (regulating, purchasing, delivery) are an attempt to recover this power. They are mechanisms for determining in specific concrete situations who is entitled to what from whom; and a means of ensuring that no deviations from this pattern occur. Their emergence fits into the critiques of social utilitarianism by theories of justice made central to public debate by the work of John Rawls. New public sector structures were above all else a way of imposing rules of distributive justice on public organization. This is why there was so much talk about 'rights', 'expectations' and 'entitlements'. Structure is about giving to each person what they are owed, and taking from each person what they owe others. No more and no less. It was the end of the free lunch.

\section{Organization as logistics}

A crucial feature of the new mechanisms is their connection to 'the market'. The point is not merely that this is the paradigm of efficiency, but that it also simultaneously allocates to everyone whatever it is to which they are entitled and clearly and unambiguously demands from everyone what is expected in return. Regulating, purchasing and delivery mechanisms combine justice and productivity in the same way that public administration connected it to democracy. New Right ideas about public sector organization separated off issues about the effectiveness, efficiency and economy of one kind of activity - that of production or manufacture - from others. Production is properly regulated by the market, on which the state acts as a purchaser of goods from suppliers, who signal their superiority (as producers) over others by offering them at a lower price. In purchasing, the state must choose on the basis of lowest price. This implies privatization where possible; but if not, the recruitment of state manpower on the same lowest price basis can achieve the same effect. It was of, course, always recognized that there were special circumstances which produce 
market failure (natural monopolies, collective goods situations, etc.). Whether the activity is public or private, there will be need for the state as regulator, eliminating the distortion of the real market from an ideal one.

Once goods and services have been obtained, there is the quite separate issue of their assemblage in packages and their delivery to those to whom they are entitled: the logistic problem. To treat this as separate means again that there is a clear and unambiguous standard by which the actions of those involved may be judged - a different kind of effectiveness, efficiency and economy. This kind of state has been called (by Derrida) the 'post(al) state', because it is post-bureaucratic and engages in delivering packages to various addresses at appropriate times. The school teacher, for instance, ceases to have a 'territory' and 'duties' which define the extent of his or her powers: a sphere of professional power which gave the right to decide what was to be taught and how. Instead, teachers become postmen and women delivering a package to the pupils in their class. They are judged by how well they have made the delivery, something which can be discovered by testing how much sticks in the pupils' minds. But teachers do not play a role in producing the package or controlling its contents. That is decided elsewhere: the choice of producer and the product itself is something which takes place elsewhere; by purchase, preferably on the market. Should the package turn out to be wrong, no blame is attached to the teacher: one does not blame the postman for the contents of letters received. Pay and promotion comes with productivity of delivery; nothing else is relevant.

There is a central thrust in these changes. They make possible clear and unambiguous standards, precise and specific expectations, for every single role in the public sector. This is in place of the previous confusion of standards; or even worse, the self-definition of expectations. The logistic framework makes clear what kind of existing structural models should be emulated and why. This would be of commercial rather than industrial establishments (from supermarkets to restaurants - the public servant as waiter proffering a menu). The other significant model is the armed forces, where the logistics of 'targeted delivery systems' has long been of central concern. This is not mindless imitation for the sake of appearances but an exploration of problems which are similar in nature. Whether as target of an educational postman bearing parcels or of the police marksman bearing retribution, the citizen has acquired a new relationship to the public servant.

\section{The new 'organization'}

The new structural forms interpret and evaluate all public action as the definition and enforcement of justified expectations. The same arrangement simultaneously ensures effectiveness, efficiency and economy of effort. In appearance therefore the organizational issue simply disappears as a separate concern. Structure guarantees performance, the way it did before. The paradox, however, is that wherever these new structures are introduced, there immediately follows a veritable explosion of organizational innovation. This has generated the most creative and interesting developments in Western public services for many decades, given that solutions to them can no longer take the form of a return to the older 'bureaucratic' practice of securing an extension of official power to resolve them.

One development has been an increased interest in public service ethics, not as a way of justifying official power but as a supplement to it. Not since the 1930s has such serious thought been devoted to the contents of a 'public service ethics' (for an analysis see Pollitt 1990: chapter 6), the spirit in which public servants go about their work; nor has there been for long as open a debate about the need to combine political democracy and official power (Etzioni-Halevy 1983; Wamsley 1990). The work, among others, of Helen Boss, has raised significant problems about the distinction between productive and unproductive activities in contemporary theories of the market in an attempt to show that the latter are often deserving of reward. There has thus been constant questioning of the fundamental argument that economic efficiency and ethical justice meet in the market. If they do not, state intervention must involve more than regulation.

A second important development has thus been an enormous flourishing of interest in what might be called 'non-structural' forms of organization in the public services. Notable among these are two approaches to organization, the Organizational Theory approach ('OT') of sociologists and the Organizational Development approach of social psychologists. The first focuses on those systems of exchange relationships which largely depend for their survival on the benefits of participation of all those involved. These 'networks' are explicitly seen as quite distinct from either hierarchical or market ones. Schools, for instance, are a likely breeding ground for networks between heads and teachers, teachers, pupils and parents. Even where schools are structurally placed in a competitive relationship, it is quite possible for them to form networks within or even against hierarchical superiors, even if only to ensure that adequate time is given to respond to the 'market' for educational entitlements. The point about networks of exchange is that they break out of the market model of the discrete purchase and sale of commodities at a particular instant, with the future discounted. The time scale may be longer, it is not money that changes hands, what is given in return need not necessarily go back to the person from whom it is received, achievements not structurally recognized may be rewarded and so on. 
Such networks require organizers who initiate them and act as brokers in the constant bargaining and renegotiation required for their maintenance. A related development is the phenomenal interest in the social psychology of organization, partly concerned with groups and 'teams' but also preoccupied with the dynamics of 'organizational leadership'. The relationship between leadership and hierarchy is an ambiguous one. Without leadership, the relation between superior and subordinate becomes an organizationally lifeless process of policing performance. But it may extend to what are lateral relationships with a hierarchy or it may even be, at certain levels, the hierarchical subordinate who leads the superior.

Changes in structural ('formal') organization have lent an increasing significance to what used to be regarded as 'informal' organization as the key to making organizations work. This produces what might be called a 'decentring' of public sector organization. In the bureaucratic era, government was thought of as at the centre and public sector organization could be understood by a series of lines drawn from this centre. This gave the impression of a single, comprehensive, harmonious and permanent system of public sector organization. The structural organization of the public sector has become the solution, specifically, to the allocative problems of government and consists of the use of means available to governments alone, the granting of rights and the imposition of obligations. Public servants now have their own distinctive organisational problems; and these are not the same everywhere, do not require overall coordination and will vary over time. In this sense there is no longer such an issue any more as that of the organization of the public sector. There is perhaps a common stock of organizational remedies but what is taken from it will vary.

\section{The third sector: a relevant model?}

The other important and perhaps unexpected development over the past decade has been the growth of preference for organizations which if they are nonstate are also equally emphatically non-profit. There should be no problem in theory about integrating these into the new public sector either as producers or as delivery mechanisms. In practice though, as is shown by governmental reaction to the enthusiasm for NGOs in the Third World, there is the basic structural problem that such organizations produce an ideology that they are organizationally superior precisely because they are non-market and non-state. There are things, in other words, that can be done only by distancing oneself as far as practicable from the existing forms of state power and property; from 'structure' as now conceived.
It is indeed noticeable that non-profit organizations thrive on a distinctly relaxed attitude towards power and property, with no attitude except perhaps that there should be less of both: things should belong to those who need them and the puople should be allowed to get on with their lives without interference from governments. Not surprisingly, this is not an approach which finds much favour with either governments or the propertied élites.

From an organizational point of view, however, the issue is far from being clear. Those who organize within a structural framework become very aware of the restrictions it imposes: the greater freedom of the third sector is very appealing. There is some interesting work (Coleman 1990) which shows that how much time spent in conventional forms of organization is a matter of assembling a diverse complexity of property rights, legally enforceable or otherwise, into a single container. The implication is that property rights should be changed to adjust to organizational functioning rather than the other way round.

This issue has come to the fore for instance in the problem of scale of operations, the 'small is beautiful' debate. How many levels of hierarchy are possible, how extensive a division of labour there can be, how much complexity can be packed into rationalization, how increasing size affects the relation between organization and environment, are organizational questions which have never received a satisfactory answer. Roberto Unger has assembled a great deal of evidence to suggest that the dominance of large organizations, public or private, cannot be explained by their effectiveness or efficiency (Unger 1987), but is the product of authority and property structures.

The actual record of large organizations seems to suggest a quite appalling inability to recognize the point at which they need to change themselves fundamentally. It need only be pointed out how the institutional structure of the Welfare State, for instance, was built up out of imitation of the organizational structure of voluntary bodies which showed first by experiment how things should be done. It is not at all implausible to suggest that distancing organization from power and property provides insights much needed in public sector organization. The old administrative questions about the productivity of structure reappear in a new negative guise.

\section{THE MANAGERIAL ROLE IN THE PUBLIC SECTOR}

I have distinguished structural from non-structural organization within the new public sector arrangements. 
The former is a set of relationships to government; consists of expectations or entitlements; is governed by rules of distributive justice; and is enforced by sanction. The other consists of relationships between public employees or between them and users, clients, customers or suppliers; and is sustained by a mixture of moral suasion, mutual benefit, arbitration or appeal to some valued external model of voluntary association.

The point at which the two meet, the crux around which the whole problem of public sector organization now revolves, is the role of the line manager. It is through them that neo-liberal reforms are introduced; they staff the structural mechanisms and police their observance. Governments in the 1980 s were, as Pollitt puts it, 'above all concerned with control ... achieved through an essentially administrative approach - the fixing of effort levels that were to be expressed in quantitative terms' (Pollitt 1990: 177). Innovation was thus quite selective, focused on the sanction of dismissal and the incentive of performance related pay, on financial control, performance-reporting knowledge systems and on budgets as instruments for decisionmaking on 'priorities' (i.e. administrative rationing). In the current 'managerialist' ideology, managers are government's 'servants of power whose task is to extract more for less; to speed up the logistic process; and be moralistically sanctimonious about the fairness of what ehy are doing. They are the structural police of the new order.

But at the same time their job extends beyond policing to the organizing of work. The latter involves control but cannot be reduced to it. Management in this sense has a dual role, and it is the way these roles are performed that has become one of the centrepoints of the neo-liberal programme. For some authors indeed the issue of the quality of management is the prime issue, and the movement from state to market a means towards its upgrading rather than being an end in itself.

On this reading, privatization is important because it creates the scope for managerial autonomy to organize work more effectively. The same is true of the new agency relationships and internal contracts. All of them confine the influence of governments to narrow, well defined channels, and remove the public sector rules and conditions which constrain optimum managerial practise, (Moll 1989). This requirement of mangagerial space is equally important in the private sphere. A writer like Eaton goes as far as to see structural reform in public organization as the means towards better management in society as a whole. 'Small and medium sized enterprises can be more efficient than large and often highly centralized organizations' he writes, and the new contractual and privatizing powers of the state can recognize this through their allocations (Eaton 1989).
These perspectives highlight the fact that though the new public service managers may not make claims to the authority of the British-style generalist administrator, they have no less autonomy than the traditional bureaucrats. It is in the way they use this autonomy, and in the managerial strategies they decide to follow with respect to their dual role, that the key choices lie.

\section{The management of work}

The first forms of public management over 250 years ago were based on the tasks of tending or caring for the assets of the ruler, thought of then as consisting of land, bullion and a large population educated in the ethics of public duty. With the rise of the factory, these methods were transferred to the task of organizing work and workers. Managers were concerned with the problems of work in general, work as work, as opposed to the specificity of work, work as the production of a specific outcome such as that of the craftsmen. The introduction of machines tended towards the elimination of the specificity of work and reduced it to Marx's 'abstract labour'; as this became a commodity like any other the problems of management became those of extracting as much as possible from the labour time which the master had bought.

Yet as the work of the first great factory manager, Robert Owen, shows, many other elements can be involved (such as his nursery schools). There is no necessary impulse towards the elimination of the specificity of work, in the shape of a specific craft, profession or occupation. The origins of 20th century administrative science itself started from the treatment of the highest administrative functions as a kind of work, which should be organizationally managed like any other.

The link between structure and organization lies here, in the connection between the setting of expectations and managerial styles of organizing work. Work as work is the only human activity to which the criteria of effectiveness, efficiency and economy of effort simultaneously and unambiguously apply. This is what the organization problem is all about. Contemporary resistance to 'organization' is not only to the bosses, but also to work. Radical thinking looks towards the 'abolition of work' (Gorz 1989) and amuses itself with re-writing the Communist Manifesto: 'Workers of the world .. . Relax' (Black 1990). Non-radical responses to work see it as an unfortunate break between periods of leisure. The work ethic has supposedly disappeared: effectiveness, efficiency and economy are no longer experienced as a valuable contribution to substantive work, as ends in themselves. There are human activities which are regularly claimed to be 'higher' than work, although the best poets and composers speak of the work they have to put into producing their works. The 
free lunch is something that is obtained without working for it. It is not surprising therefore that governments faced with parasites and scroungers should turn to management to solve their problems: their role is that of imposing discipline on work, in the sense of extracting labour in return for market-set monetary reward.

\section{Technique}

Yet it is quite inadequate to imagine that this is the only possible managerial approach to work. There is something truly bizarre in the revival in our day of older doctrines of work, whether it is Smith's liberal notion that work is painful and engaged in only for fear of starvation, or Habermas's romantic notion that work is dumb, silent effort, inferior to the playful ('ludic') communicative interaction of art, scholarship or politics.

The problem is that modern management has, at least since the 1920 s, by-passed these issues. The central concerns of modern managerial practice are perhaps best understood as the attempt to interpret work as the performance of 'technique'. Management is itself technique: people long ago stopped talking about 'organization' in favour of a body of technique of 'organizing'. But management is also the transformation of the activities being managed into a body of technique. To the manager, whatever it is you are doing, whether constructing a road or making love, there must be a technique for doing it. Although undoubtedly figures of power, managers are also educators, teachers, trainers in technique. They may be concerned with extracting effort, but only by and through the techniques of motivation.

This takes us to the more substantial problem about management: there are few things more threatening and dangerous than the reduction of human activity to the performance of a set of techniques and the reduction of human relationships to quantitative formulae. What is new among public services in the Western world is not merely an interest in informal organization, but also a culture of technique. Bureaucrats have become technocrats. This seems to hold for the contexts which I have examined. Developments like the 'public management' movement show that this culture is now well-established; and with it the revival of a powerful work ethic and the demand for further training in technique without which modern management is impossible.

The 'other' side of their role has thus also involved finding ways of understanding work as technique: what it is, how it is used, how it is learnt, how and why it embodies a quantitative or 'formal' element (logicomathematical operations) and, above all, the problematic connection between technique and ethics which shows how human beings can satisfactorily relate through the apparatus of technique. Technique is the other, the alternative way, of securing the effectiveness, efficiency and economy that governments optimistically expect to be an inexorable structural effect.

\section{Organization and its context}

Since structure and organization always go together in public sector arrangements, it is unproductive to define each in isolation from the other. This is of course to deny the utility of timeless general theories of each, whether this takes the form of the universal truths of the science of administration or an equally universal set of rules of distributive justice. As the recent debate about the latter shows, there is no more reason to expect agreement on what is and is not 'fair', than there is on whether an action conforms to a social calculus (Pratt and Zeckhauser 1985).

Although in one way this is obvious enough, there is in fact immense resistance in Western societies to the notion that public sector arrangements, structural or organizational, are historically transient: that they come and they pass away. Hence the inability to interpret neo-liberal mechanisms as simply without precedent, not like any other model in the past, nor that they are a response to the transient primacy of particular issues and will in due course be replaced by others.

This is an unfortunate attitude because it blocks recognition that contemporary public management takes the organizational issue into hitherto unknown territory. The questions are going to be as unprecedented as the answers. This stands to reason because the organization of work has to change in sympathy with the great orthodoxies of today, liberal individualism, representative democracy and free market economics. These give remarkably little recognition to either work or organization. They have put an end to a generalized if sullenly resigned acceptance of the demands of organization. Not long ago, commentators pontificated about the Age of Organization and agonized about being trapped in Weber's iron cage. Organization was The Solution to every problem; it brought peace, prosperity and progress. Now there are just the State and the Market.

Organization, in other words, has to mean something quite different now because it has to establish itself by displacing either hierarchy or market. Where encounters between self-interested and opportunist strangers (Williamson 1986) are the norm, there grows up the expectation that the alternative to fleeting spontaneous co-operation ('the market') can only be the result of exercising 'power', by threat, coercion or manipulation. The structural organization of the public sector closely restricts the manager's access to structural rights over 
money and sanction that would enable them to form autonomous market networks or hierarchical structures. Nor is it the case that, faced with any difficult situation, there is an automatic readiness to hand it over to the nearest bureaucrat for solution. The key choice now is not between better or worse organization but between its presence and absence. Organization is now implicitly or explicitly judged as against other alternatives. The agenda facing the manager as autonomous organizer is always: why any organization at all? Why not simply do without? 'Organization' is now something distinct from either market or hierarchical connection, needed instead of them.

\section{Managing with structure and organization}

When the two sides of neo-liberal public sector mechanisms are taken together we are left with an organizational function which is really quite distinctive. We would expect, and do find, that what is important about structure and organization, is how they bend towards each other in a distinctive way. One crucial area of flexibility is to question whether the supposed line of command in the public sector is in fact best thought of as a form of hierarchy at all. The situation is not clear-cut, because the expectations of the manager are two-fold: the first (the anti-parasitic element) relates to means, but the second (target setting) relates to results, leaving managers free within limits to find their own means of achieving them. The first conforms to the classic hierarchical relationship between master and servant; but the second is the relationship between principal and agent ( $\mathrm{cf}$. the motor car manufacturer and the dealer or a company and its franchise holders). This relationship (which pushes us beyond Williamson's market-hierarchy distinction) has been a recurrent theme in thinking about organization in the 1980 s and represents precisely that distancing from market and hierarchy which is now such a feature of new thinking about organization-as-network (Pratt and Zeckhauser 1985; Schaffer's much earlier reformulation of the problem of administration as that of agency, 1969; and the New Public Administration's complete reliance on the 'agency perspective' in Wamsley 1990).

This is something which governments themselves have been most keen to promote: the regulators, the purchasers and the logistic side of government, the providers, the deliverers, have been forcibly hived off as, significantly, 'agencies'. The relationship is neither that of market nor of hierarchy, although of course there is a tendency for governments to attempt to enjoy the benefits of both simultaneously.

There is therefore, it is argued, a potential space for 'organization' in the new situation; one which can be levered open further by determined action. Wherever public employees treat governments as just 'politicians' (something very common in my experience) there is a quite marked distancing from governments which one would expect from an agent rather than a servant. There is thus a real issue about whether in the old sense there are any public servants left; or whether even the relationship between governments and public employees should now be thought on the model of manufacturer and dealer or lawyer and client: each with their own distinct interest and perspective, a relation with a distinct element of mutual dependence rather than subordination. In such situations, public managers will not hesitate to point out that they work within the limits of political decisions for which they themselves take absolutely no responsibility and may even semi-publicly disagree.

\section{A new technocracy?}

The other organizing side of public management also contains room for manoeuvre. However, if there is a space to be filled, what is going to fill it? Through organizing work, the manager comes into contact with other professionals. The policing role is not the only option. There is the alternative of forming a technocracy, an alliance between one body of technique and another. Managers offer here an interpretation of work as work which is validated by its effects; better medicine, engineering or teaching. This form of technocracy must be thought through anew, precisely because it is distinct from market and hierarchy; competing with them for space by offering something they cannot achieve. There exists no contemporary account of technocracy along these lines, although historically they were quite common and played a significant part in the emergence of a science of administration in the United States, suggestively attached to the democratic ideology of the "common man'.

\section{Coming to our senses}

The analysis of neo-liberal public sector mechanisms has left us with two key concepts, 'agency' and 'technocracy'; and the suggestion that the extent of the space created by them and what happens in it is dictated by how public managers carry out their complex roles, what have been called 'managerial styles' or 'strategy'. This is the crucial regulating element, now as important as issues of public policy or who gets elected to public office.

The key issue is thus how everyone (governments and citizens as well as managers themselves) come to terms with the novelty of the extraordinary train of events which has turned choice of management strategy from an obscure preoccupation of experts into a quite fundamental question in the public realm. Public managers, unlike their private counterparts, have a residual inclination towards decent obscurity rather 
than an exposed position in the public eye. Governments and citizens have a residual ignorance and belief in a return, in one way or another, to the fundamental truths once possessed but now lost. It is a matter of approach: whether these are matters to be discussed in traditional terms at the end of a long queue of items waiting to be resolved by those before them; or whether they are unprecedented, at the frontiers of a post-modern age, requiring a whole new language.

\section{Back to work}

There is no better place to start than with the most radical and most critical body of work on management and organization: the body of writing known as 'Critical Theory'. It has already been suggested in the case of Habermas that this approach is, in a new context, simply not radical and not critical enough. It is disqualified from contributing to the essential questions today because peculiarly it is prone to regard work as something inherently oppressive and secondrate. The knowledgeable Claus Offe, for instance, goes so far as to suggest the decline of the centrality of work in advanced societies, and even offers the prospect of its disappearance as a kind of liberation (Offe 1985).

Paradoxically, it is what Critical Theorists have in common with their opponents that needs most questioning: the notion of technique as something that goes on 'in the mind', that what is wrong with the 'instrumental rationality' of technique is somehow a distortion of human reason. With this goes an intense distaste for applied mathematics; and a down-grading of any intellectual not in command of the works of Kant and Hegel, between whom the future of humanity is fought out; rather than through struggles about piece rates, time and motion analysis or the definition of cost centres.

The argument here, however, is that if work (and hence organization and management) is to be taken seriously as a problem, thinking must take a post-modern direction and look in precisely the opposite, mundane direction: to technique as something that happens 'in the body'. It is the language of better bodies rather than of better minds that is now needed.

\section{Work and the body}

One of the benefits will be a greatly increased sensitivity to the language ('discourse') in which structure and organization are commonly spoken about; not in official reports but in the hurly-burly of everyday interaction. Clearly the body and everything that it brings with it is part of work: the kinaesthetic awareness of bodily movement, the senses, feelings, skills, imagination, sensitivities, judgement. Modern organization, structural or vocational, presupposes a human base of a particular kind: people equipped not merely with a specific body of technique, but a body in which all these human capacities are mobilized in learning, using, assessing and replacing any technique. Structure and organization hook quite deeply into the body in this sense.

The significance of discourse goes beyond this point, however, to extend to the interpretation of the metaphorical nature of everyday language about success and failure in the acquisition and practice of technique. The former has been spoken of since the days of Dr Frankenstein's monster as making the body into a 'machine' (Winner 1977). The metaphors of public sector organization as a machine or as the 'machinery of government' are well-known. This is however only one way of bringing in the body. Despite the sometimes excessively voluntaristic and optimistic tone of the standard managerial vocabulary, organizations are in fact deeply problematic, riven by quite intractable difficulties which resist all attempts to resolve them. There is something unexpected about them; the actual problems encountered in public sector organization are never those one might have anticipated from organizational blueprints and the solutions do not lie in moving in the opposite direction (cf. the endless movement from centralizing to decentralizing impulses). In the language of organizational despair, spoken rather than written, such impossible situations are conventionally accounted for by treating the body as a negative, limiting, or even destructive element in organization. The ethics of structure, for instance, is spoken about as over-ridden by bodily impulses such as greed or emotion; impersonality is undermined by affective bonds with kin; rationality is limited by the limitations of the human brain; enlightened long-term interests by shortterm impulses and so on. Here the body has become both opaque, an unmovable obstacle and a cause of disorganization, the lack, absence, of organization that should be there.

The category of 'body' here is not necessarily physical; it stands simply for something which cannot be understood and cannot be coped with. Not knowing its nature and origins are part of the problem. It could therefore be something physical; it could be a cultural trait learnt so early that by the time the adult joins organizational life it is fixed; it could be a fundamental personality trait; it could be the effect on the individual of other non-state social relationships in which they are involved; or it could be something else which can only be guessed at.

\section{Management strategy as a critical concept}

The argument has thus unexpectedly carried us to an interest in the unguarded everyday utterances about structure and organization; of which we are all aware, but to which no particular significance has been 
imputed. There is a positive language of success, one in which we describe ourselves as 'machines', devices for doing things. This is not meant as criticism, but praise. Then there is a negative language of failure in which we find people - including ourselves - so unresponsive that we project our shortcomings into the dark interior of their bodies. There is something here that should be but is not within reach of organization.

It is only recently that we have begun to grasp what this strange, metaphorical language actually means, what it is all about. We owe our grasp of it to people with a vested interest in finding out, those whose critical thinking arises from the special significance they or others have attached to the human body: ecological thinking for which the body is the link with nature; a peace movement which feels deeply about the suffering and death of bodies; and all those whose bodies have been treated as the cause of their inferiority: feminisms which want to validate the female body, the gay and lesbian movement asserting pride in their bodily impulses and the anti-racist movement for whom White racial prejudice in its subtle forms is the product of a European and Christian culture unable to resolve the relationship between body and mind.

The response to the discourse of these movements is a reasonably accurate indicator of where individuals locate the organizational problem: whether it is to be resolved by the timeless truths of the past or constitutes something novel, to be responded to by invention, something that can only be done by inventing a new language.

Take the racist behaviour of British policemen. Is it an irrational force in the bodies of the individual policemen? Or is it an organizational problem, indeed the effect of the organization of police forces. Should it be responded to by severe sanction and regret that they do not work? Or should we listen to the racist language of the British policeman and 'deconstruct' it until we know what it means? What is it about the machines they are which breaks down and is then projected as something intractable about bodies which happen to be young and have Black skin? How can we explain structurally, organizationally, that policemen are machines with feelings: an intense anger that unleashes from time to time into an irrational explosion of violence? Do we send them to prison or teach them a new language?

The same dichotomy applies to 'success', which, as those who have encountered it will know, is no less mysteriously accounted for by those who achieve it Who really knows for instance when the trains do run on time, what machine-bodies have been made to make possible this astounding organizational achievement? How is this done: the discipline of the market, self- control over their own bodies, incentive payments, the fear of dismissal? Those determined to get, so to speak, to the bottom of the achievements and problems of organization will have to engage seriously with a managerial practice that in a very obvious sense has consisted in Governing the Soul (Rose 1989).

\section{Social Darwinism and the manager}

The public management style of the 1980 s has been described as 'macho, with the really tough guys wearing their red underpants outside their trousers just like Superman' (Koch 1988: 210). This, as will have been noted, was spoken about by those who promoted it, in terms which represented a parody of Darwinist evolutionism (Moore 1986), with different categories of the managed as distinct biological species arranged in hierarchical order, each with their ecological niches and innate survival traits: nature red in tooth and claw extended into the office. It is the language of the cult of managerial discretion that says it all: disposing of dead wood, terminating shelf-life, it's a tough world out there, we don't owe anyone a living, kicking arse, efficient killing machines, when the bottom line comes, man eats man, let the bastards sweat, tough-nosed decision-making. Management is survival technique. Listening to the discourse is worth all the text-books on management theory (or any other) combined.

It is inadequate merely to condemn, to moralistically say that it is better to be tender rather than tough or dismiss this as a variant of the more important languages of market or of hierarchy. What is described is a machine which brings into being a set of organizational arrangements inserted between market and hierarchy. Only another way of doing this is a relevant response.

\section{Better management: better bodies?}

The present situation classically illustrates something well-known to the great writers on organization in the past, from Weber to Mary Parker Follett: that serious organizational innovation involves a challenge to the culture of societies and economies. Despite the language of radicalism, the social Darwinist style is culturally extremely conservative. To go beyond it requires what amounts to a cultural revolution. The initial step towards satisfying this 'post-modern' agenda is to produce a language in which it is comfortable and mundane to incorporate into technique a whole range of things which have been excluded: the relationship to the human body as solution (the machine) and as problem (the body as resistant, or as 'object of power' as Foucault calls it); incorporate into the account of relationships the connections between human bodies; and the bodily relationship to the world, its movement through space and its change through time. This is technique in the sense in which there is a technique to playing tennis, 
composing poems, Indian dancing or transcendental meditation; or, to make the point as bluntly as it is possible to do, the technique of Tamil astrology, making love or pottery as a craft. It will be as shocking in our day as the Protestant ethic, the bureau, the London Transport Executive or TVA in their day. The issue is that of culture itself: what it is that is in some sense learnt as opposed to that which has to be taken as merely given. The key problem is about the manager as pedagogue, learning about work, teaching about work.

\section{Staffing}

This is not something that needs to be thrust upon the public sector today. Even without an explicit change in language, most of the currently live issues in public management, resolve themselves into a choice between depending on what is organizationally given as against what can be transformed by an internal pedagogic process of some kind. In staffing (recruitment, promotion, pay systems) this takes the form of questioning the validity of systems grounded in selection of those with 'natural ability'. What happens when rapid promotion opportunities are opened up, pay becomes performance related, external rectruitment and short-term contracts are made standard and the techniques of position classification make possible constant mobility into and out of the organization, is to validate selection on the basis of 'natural' ability to perform a well-defined task: that is those which the particular organization simply finds embodied in candidates as they present themselves (in the 'stamina' displayed in their 'track record').

At the opposite extreme are staffing systems in which it is assumed that all the abilities and capacities required will be provided by organizational training and experience; and selection is thus concerned with detecting the educability of candidates over some fairly extended period of time in a sequence of different organizational tasks. The contrast between the two is expressed in cultural terms by accounts which portray organization as a hierarchy reflecting innate superiority; and at the other extreme an image of an organization which tries deliberately to compensate for 'external' factors and judges itself by an increasing levelling of ability to perform over time.

One writer whose work needs re-evaluation in this context is F. W. Taylor, not a popular man in more radical circles. His work nevertheless contains a levelling impulse. His methods represent a way in which the work of a person of outstanding natural ability is translated into a set of techniques. The point of course is that these techniques can then be taught to others, who can produce approximately the same results without the same natural ability. As is wellknown, Taylor envisaged the same levelling process operating at higher levels in the line of command.
'Fordism' as an organizational formula, to take another instance, could hardly have become the object of widespread imitation if it depended on finding people as extraordinarily gifted as Henry Ford (cf. Weber's routinization of charisma). The problem is thus to recognize abilities which to any particular organization are a given; and spread and generalize them. To do this the organization must necessarily deconstruct what lies behind the appearance of a natural gift and create a culture in which it is not something that is permanently by the individual concerned for the use of which he is rewarded.

The converse case of 'natural disabilities' also applies. Whenever such traits are discovered to be widespread, it should be possible to discover in what they consist and how they were produced. The target should then again be a process in which performance levels out over a period of time.

The same issue also comes up in making connections between organizations and the system of technical education in a particular society. The question is that of which determines which. One way of seeing the relationship is that technical education is a set of opportunities for individuals to acquire abilities which they then sell to organizations on the labour market. It is thus for employers to decide what body of technique they will introduce in their organizations. At the other extreme is the notion that all organizations are required to install a publicly defined optimal technical apparatus and must adapt their structure and organization to its requirements. This apparatus would not then be the property of any individual or organization; it would level out technical standards throughout industry and thus competition between organizations would be fought out on how well this commonly available technology was being used.

\section{Techniques of motivation: the revaluation of 'pleasure'}

For those who are 'successful', the issue of motivation does not seem to arise. This however leaves open the question of the larger part of the work force. Here it is not so much incentives that are important as sanctioning. There has here been some important work, principally by Foucault and Donzelot, on the mechanics of organizational punishment. This work suggests that the analysis of sanction as the infliction of pain, as deprivation, is a serious misunderstanding. We have here again to note the distinctiveness of organizational solutions notably from those of a sovereign power (the classic hierarchy).

Foucault shifts the stress to the techniques of surveillance ('inspection' in British terminology) and the development of 'norms'. Control, they argue, is achieved by being seen without knowing who is 
looking, or even whether they are. He argues, and the organizational literature seems to provide some support, that organizational sanctioning consists of detecting and removing people who are abnormal (do not 'confor m', in an older vocabulary). This is not the implicit Hobbesian threat behind the law of a form of moralistic condemnation; on the contrary it is achieved through a spurious tolerance in which the abnormality is treated as something outside the control of those disciplined (i.e. something embodied in them). They are not punished for being willingly disobedient or immoral: merely being sent off to some other place better suited to their unfortunate condition (cf. the 'tolerant' approach to the defects of women, gays, Blacks: don't blame them, they can't help it, its just the way they are made).

This conventional organizational discipline does not distinguish between an élite motivated by higher purposes and a mass motivated by material incentives. For one thing it is the élite which receives material rewards. For another there is a levelling impulse which extends ever upwards. As de Certeau put it indeed, the advent of this anthill society began with the masses, who were the first to be subjected to the framework of levelling rationalities. The tide rose. Next it reached the managers who were in charge of the apparatus, managers and technicians absorbed into the system they administered; and finally invaded the liberal professions that thought themselves protected against it . . ' (de Certeau 1984: 1). There is a tendency for everyone to become a merely 'ordinary' person; whatsoever is characteristic of the avant garde, the extraordinary, is soon absorbed and converted into something which an ever increasing number of ordinary people can do.

Another way of putting this is that ordinary people become organizational machines. A machine is a device which although its actions look as if they are purposeful in the sense that they produce a result, they do not in fact have a purpose; they work in a particular way whenever provided by some kind of energy or fuel. In conventionally established modes of thought, people are not supposed to be machines, to be motivated by purpose, not some cause. The neo-liberal selfinterested economically rational man is among other things an offer to escape from this mechanical condition: the small businessman being the lowest rung on the ladder of escape, the man who 'becomes his own boss'.

It would be wrong to deny that this theme has a very strong hold on Western cultures. Foucault is one among a number of writers who rejected any form of liberation which consists of an attempt to escape from the condition of ordinariness. His version of gay liberation for instance consists of making homosexuality as ordinary as any other sexual preference; and no more remarked upon. This strategy, followed by a number of other writers, abandons the ideal of the purposeful liberal individual, interconnected through the market, in favour of a critical deconstruction of the fuel which drives the machinery of ordinary people: pleasure and pain. Both are commonly treated as embodied, the most private of experiences, to which only individuals themselves have access, a powerful force intractable to organizational manipulation.

As Colin Mercer has shown in the British case (1983), there is here a whole cultural complex which blocks the way to a reshaping by managers of work as a source of pleasure in competition with monetary compensation for an unpleasant necessity. Strangely enough, the sources in British culture for an alternative turn out to be located in conservative traditions of thought, such as Burke's conception of 'sublime' pleasure which 'causes the body to draw together in reaction like a fist, in exercise or labour; and labour is a surmounting of difficulties, an exertion of the contracting power of the muscles; and as such resembles pain, which consists of tension or contraction, in everything but degree'.

\section{Routines and routinization}

With the right (rather than the Right) approach there are now opportunities for managerial innovation in the most unlikely places such as the 'value for money' efficiency drives of recent ycars. One of the effects of this has been to reformulate public action in the format of what have been called 'programmes'; the older concepts of directing have given way to the techniques of programming. Programmes are of course a classic method of providing precise and unambiguous performance targets and allocating responsibility for non-compliance.

Yet even this apparently unpromising set of devices has been turned round to serve as a solution to another organizational problem, that of routinization. In the standard Weberian formulation, this is achieved by imposing 'rules' on public servants. There are however better and worse ways of applying rules; some mechanical and literal applications are a recipe for disaster ('mindless' behaviour, 'ritual' performance). The difficulty is how to combine routinized behaviour with non-routinized people. Programming offers the alternative of guidance through setting objectives or targets, formulated in such a way as to convey to public servants the point of their activity, the aims behind what they are doing. Negotiating these with the managed can be very helpful on both sides, helping the programmer to understand the actual ways in which work is carried out and providing for those who do the work a task definition which stretches and develops their existing skills without imposing a markedly heavier work-load. This would again seem to develop the situation into a pedagogic one. 


\section{Information and the senses}

What is called 'information' is perhaps the epitome of the disembodied in current organizational practice: human knowledge taken out of people and into nonhuman computing devices. There has been a constant problem about how adequate a representation of the world such information systems actually provide. In the work of Baudrillard these issues have been pushed to the point of arguing that representations of reality altogether displace the reality itself (the issue of 'virtual reality'). Once absorbed into organizational functioning a definition of reality itself acquires more reality than the original, if indeed there ever was one.

One of the more interesting responses to this situation has been to take attention away from the hardware in knowledge systems and focus on the people who operate them. What emerges from this concern is the extent to which organizations work by educating, developing, or extending the bodily apparatus of human perception itself: both the outer senses sight, (how people 'see' things when they look at them) hearing (what they hear when they listen to people), touching, even smell; and the so-called inner senses (e.g. awareness of bodily states like emotions). Older conceptions of craft skills described them as developed forms of these senses.

Deskilling is not the only alternative to the practice of craft. It has been pointed out that musical skill develops through the additional capacity for translating qualitative differences of sound into a mathematical formalism. There is in fact a whole range of technique (e.g. playing tennis, acting on the stage, Indian music, transcendental meditation) in which bodily operations are performed through some formal apparatus. Furthermore, there is also a long history of extended perception through instrumentation, such as telescopes or cameras. Bergson developed the theme that all perception is powerfully affected by human memory (Gane 1991). There have recently been a number of histories of perception (Lowe 1982; Gifford 1990).

What all this is working towards is a reinterpretation of the forms, of communication characteristic of organizations (tables, graphs, maps). Foucault developed important ideas about the connection between the emergence of statistical thinking and the definition of government as the management of 'populations' (e.g. in the work of Ian Hacking). Some recent analyses of Aids campaigns have analysed statistical analyses as a distorting intermediary between governments and a major social problem. The point of this work and such things as 'communication audits' (Booth 1988) is to reconnect organizational knowledge with the bodily perception into which all actors in fact translate it when they interpret information.
The critical point is that these interpretations involve notions of what perceivers ought to have perceived, rather than what they actually did perceive. What this implies is that management involves the task of extending and transforming the perceptual apparatus of organizational participants. This can work towards the suppression of perception as well. Reliance on written organizational records, for instance, involves teaching people to disregard their own personal memories as merely 'subjective' and unreliable.

It would indeed be difficult now to see an organizational mechanism like Bentham's panopticon prison as composed merely of a combination of market (contracting) and coercive (legal) relationships. The novelty of the scheme clearly lies in its pedagogic practice of modifying the bodily perceptions, inner and outer, of the prisoners. Their successful treatment leaves them aware of the 'gaze' of society even when no one is looking at them; and with images of pains and pleasures in the distant future a stronger motivation than immediate, actually present ones.

The conclusion of this work must be that managers not only have to take seriously how those they manage literally see things, but that they are involved in a pedagogic task of modifying perceptual apparatuses to integrate them with organizational intelligence. A more bodily conception of technique will help to explain the resistance to this process: the sense of disorientation caused by destabilizing patterns, the difficulties of internalizing logico-mathematical operations, the sense of intrusion into the self and above all the ethical problem of relating to other people (e.g. Aids patients) though a selective distorting intervening apparatus.

\section{CONCLUSION}

These examples of live issues in public sector organization are merely to show what is involved in the immensely difficult task of developing an alternative to the managerial regulating strategy of the 1980 s. In the literature of management the issues of culture, communication and strategy are absolutely central (Fiol 1990; Huff 1990; Handy 1991). What is claimed in this article is that the neo-liberal dynamic in the public sector has unleashed a set of relevant and important issues of general public importance. Public servants and their managers are important people whose choices have immense implications for the rest of us. Above all, there is an unresolved issue about where those choices will lead in resolving that crucial 20th-century problem: the relation of organization and democratic government. Only their fusion on a new basis offers some hope for the future. 


\section{REFERENCES}

Black, B., 1990, The Abolition of Work, Pirate Press, Sheffield

Booth, A., 1988, The Communications Audit: A Guide for Managers, Gower

Boss, H., 1990, Theories of Surplus and Transfer, Unwin Hyman

Burnham, J., 1945, The Managerinl Revolution, Penguin

Caiden, G., 1969, Administrative Reform, Allen Lane

de Certeau, M., 1984, The Practice of Everyday Life, University of California Press, Berkeley

Coleman, J. S., 1990, Foundations of Social Theory, Belknap Press, Cambridge, Mass

Dimock, M. E., 1958, A Philosophy of Administration, Harper

Eaton, J. W., 1989, 'Bureaucratic, capitalist and populist privatization strategies', International Review of Administrative Sciences, Vol 55: 467-492

Etzioni-Halevy, E., 1983, Bureaucracy and Democracy, Routledge

Fiol, C. M., 1991, 'Managing culture as a competitive resource', fournal of Management, Vol 17 No 1

Gane, A., 1991, Undoing the Social, Open University Press, Milton Keynes

Gifford, D., 1990, The Farther Shore, Faber and Faber

Gorz, A., 1989, Critique of Economic Reason, Verso

Handy, C., 1991, The Age of Unreason, Business Books

Huff, A. S., 1990, Mapping Strategic Thought, Wiley

Jacques, E., 1976, A General Theory of Bureaucracy, Heinemann

Koch, H. (ed.), 1988, General Management in the Health Service, Croom Helm

Lowe, D., 1982, History of Bourgeois Perception, Harvester, Brighton
Mercer, C., 1983, 'A poverty of desire' in Formations of Pleasure, Routledge and Kegan Paul

Moll, N., 1989, 'Contract-based management control in government organization', International Review of Administrative Sciences, Vol 55: 365-379

Moore, J., 1986, 'Socializing Darwinism' in L. Levidow (ed.), Science as Politics, Free Association Books

Offe, C., 1985, Disorganized Capitalism, Polity Press, Cambridge

Pollitt, C., 1990, Managerialism and the Public Services, Blackwell, Oxford

Pratt, J. W. and Zeckhauser, R. J., 1985, Principals and Agents, Harvard Business School, Boston

Report with Special Studies, 1937, President's Committee on Administrative Management, Government Printing Office, Washington

Rose, N., 1989, Governing the Soul, Routledge

Schaffer, B., 1969, 'Deadlock in development administration' in C. T. Leys (ed.), Politics and Change in Developing Countries, Cambridge University Press

Simon, H. A., 1976, Administrative Behaviour, Collier, Macmillan, New York

Thompson, G. et al., 1991, Markets, Hierarchies and Networks, Sage

Unger, R., 1987, Plasticity into Power, Cambridge

Waldo, D., 1948, The Administrative State, Ronald Press

Wamsley, G. L. et al. (eds), 1990, Refounding Public Administration, Sage, London

White, S. K., 1991, Political Theory and Postmodernism, Cambridge UP

Williamson, O,, 1986, Economic Organization, Wheatsheaf, Brighton

Winner, L., 1977, Autonomous Technology, MIT Press, Cambridge Mass 